\title{
Mechanism of free radical generation in platelets and primary hepatocytes: A novel electron spin resonance study
}

\author{
CHIUN-LANG WANG ${ }^{1 *}$, PO-SHENG YANG ${ }^{2 *}$, JENG-TING TSAO $^{3}$, THANASEKARAN JAYAKUMAR ${ }^{4}$, \\ MENG-JIY WANG ${ }^{5}$, JOEN-RONG SHEU ${ }^{4}$ and DUEN-SUEY CHOU ${ }^{4}$ \\ ${ }^{1}$ Department of Gynecology and Obstetrics, Min-Sheng General Hospital, Taoyuan 33044; ${ }^{2}$ Department of Surgery, \\ MacKay Memorial Hospital and Mackay Medical College, Taipei 10449; ${ }^{3}$ Division of Allergy and Immunology, \\ Department of Internal Medicine, Cathay General Hospital, Taipei 10630; ${ }^{4}$ Department of Pharmacology, School of \\ Medicine, College of Medicine, Taipei Medical University, Taipei 11031; ${ }^{5}$ Department of Chemical Engineering, \\ National Taiwan University of Science and Technology, Taipei 10607, Taiwan, R.O.C.
}

Received December 7, 2016; Accepted October 16, 2017

DOI: $10.3892 / \mathrm{mmr} .2017 .8058$

\begin{abstract}
Oxygen free radicals have been implicated in the pathogenesis of toxic liver injury and are thought to be involved in cardiac dysfunction in the cirrhotic heart. Therefore, direct evidence for the electron spin resonance (ESR) detection of how D-galactosamine (GalN), an established experimental hepatotoxic substance, induced free radicals formation in platelets and primary hepatocytes is presented in the present study. ESR results demonstrated that GalN induced hydroxyl radicals $\left(\mathrm{OH}^{\circ}\right)$ in a resting human platelet suspension; however, radicals were not produced in a cell free Fenton reaction system. The GalN-induced $\mathrm{OH}^{\bullet}$ formation was significantly inhibited by the cyclooxygenase (COX) inhibitor indomethasin, though it was not affected by the lipoxygenase (LOX) or cytochrome P450 inhibitors, AA861 and 1-aminobenzotriazole (ABT), in platelets. In addition, the present study demonstrated that baicalein induced semiquinone free radicals in platelets, which were significantly reduced by the COX inhibitor without affecting the formed $\mathrm{OH}^{\circ}$. In the mouse primary hepatocytes, the formation of arachidonic acid (AA) induced carbon-centered radicals that were concentration dependently enhanced by GalN. These radicals were inhibited by AA861, though not affected by indomethasin or ABT. In addition, GalN did not induce platelet aggregation prior to or following collagen pretreatment in human platelets. The results of the
\end{abstract}

Correspondence to: Professor Duen-Suey Chou, Department of Pharmacology, School of Medicine, College of Medicine, Taipei Medical University, 250 Wu-Hsing Street, Taipei 11031, Taiwan, R.O.C.

E-mail: fird@tmu.edu.tw

${ }^{*}$ Contributed equally

Key words: platelets, hepatocytes, D-galactosamine, baicalein, arachidonic acid, electron spin resonance, hydroxyl radicals, carbon-centered radicals present study indicated that GalN and baicalein may induce $\mathrm{OH}^{\bullet}$ by COX and LOX in human platelets. GalN also potentiated AA induced carbon-centered radicals in hepatocytes via cytochrome P450. The present study presented the role of free radicals in the pathophysiological association between platelets and hepatocytes.

\section{Introduction}

Drug induced liver injury is the most frequent cause of hepatic dysfunction. Drugs or their reactive metabolites are known to induce distinct effects on gene expression and cellular homeostasis in hepatocytes (1). Indiscriminate usage of various drugs, chemicals, mycotoxins and gamma radiation are potential threats to the integrity of the liver. In vitro hepatotoxicity methods are routinely used to evaluate the hepatotoxicity of drugs/chemicals to understand the underlying mechanisms and to establish the associations with in vivo hepatotoxicity (2). Hepatic injury stimulated by D-galactosamine (GalN) is an appropriate experimental model of human liver failure (3). GalN is an amino sugar metabolized by the hepatocytes that induces liver damage and enhances the production of reactive oxygen species (ROS) in hepatocytes (4). GalN is an ideal hepatotoxic model that resembles clinical hepatitis, in which oxidative stress serves a major role (5). GalN inhibits protein synthesis by depleting uridine triphosphate pool, causing early generation of ROS and finally apoptosis (6).

ROS are also involved in cardiovascular diseases, atherosclerosis, and various acute and chronic liver diseases (7). ROS include superoxide $\left(\mathrm{O}_{2}{ }^{\bullet}\right.$; an oxygen centered radical $)$, thiols (a sulphur-centered radical), trichloromethyl $\left(\mathrm{CCl}_{3}{ }^{\circ}\right.$; a carbon centered radical) or nitricoxide $\left(\mathrm{NO}^{\circ}\right)$. The other ROS continuously generated in vivo are: $\mathrm{O}_{2}{ }^{\circ}$, hydroxyl radicals $\left(\mathrm{OH}^{\circ}\right)$ and $\mathrm{H}_{2} \mathrm{O}_{2}$. Continuous interactions with biological systems by such free radicals either formed endogenously, or exogenously via the inhalation/ingestion of toxicants, chemicals or biological reactions, cause cumulative damage to protein, lipid, DNA, carbohydrates and the membrane (8).

Acetaminophen, the most widely used analgesic in the United States, causes severe hepatic necrosis leading to acute 
liver failure following suicidal overdoses (9). Platelets may contribute to acetaminophen-induced liver injury via their interactions with leukocytes to promote inflammation, as observed in various other models of sterile inflammation (10). Platelets contain a host of proinflammatory mediators, which potentially may serve a role in acetaminophen-induced liver injury (10). In the last decade, the paradigm of platelet function has expanded from primary hemostasis to intravascular redox signaling and sterile inflammation. Oxidative stress and the sterile immune response are considered to be prominent hallmarks of hepatic injury (11); however, the role of platelets has recently been considered in the context of liver injury. Khandoga et al (12) postulated that as activated platelets are able to generate ROS and NO, and release proinflammatory mediators, they may exhibit the potential to induce liver injury. Cyclooxygenase (COX) and lipoxygenase (LOX) products derived from arachidonic acid (AA) are responsible for microvasculature failure, and are implicated as pathogenic mediators in endotoxemia (13). Ito et al (14) demonstrated that pretreated with a LOX inhibitor in mice attenuated liver injury during endotoxemia. In addition, a selective COX-2 inhibitor improved the survival rate in endotoxin-challenged mice (15). Based on the fact that GalN is the most established model of liver disease, in which platelets contribute to the endotoxin-induced liver injury, and ROS are involved in acute and chronic liver diseases, the present study used electron spin resonance (ESR) and spin-trapping methods to detect and identify the GalN induced free radicals in human platelet suspension and mouse primary hepatocytes. In addition, as the development of inhibitors of COX, LOX and cytochrome P450 pathways may present novel insights into the treatment of free radical mediated hepato-cardiac disorders, the inhibitors were used to assess their role in regulating GalN-induced free radicals.

\section{Materials and methods}

Chemicals and reagents. 1-Aminobenzotriazole (ABT), AA861, AA, baicalein, bovine serum albumin (BSA), collagen (type I, bovine achilles tendon), dimethyl sulfoxide (DMSO), N-Acetyl-D-galactosamine, heparin, indomethacin, L-glutamine, prostaglandin E1 (PGE1), sodium citrate and thioacetamide were purchased from Sigma-Aldrich; Merck KGaA (Darmstadt, Germany). 5,5-Dimethyl-1 pyrroline N-oxide (DMPO) was purchased from Enzo Life Sciences, Inc. (Farmingdale, NY, USA).

Preparation of human platelet suspensions. The present study was approved by the Taipei Medical University Institutional Review Board (Taipei, Taiwan). All human volunteers gave written informed consent. Human platelet suspensions were prepared as previously described (16). Blood was collected from 20 male and female (7:13) healthy human volunteers 20-30 years old; all students from Taipei Medical University, Taiwan, who had taken no medication during the preceding 2 weeks, between June-November 2016, and was mixed with acid citrate dextrose (ACD, 9:1). Following centrifugation at $120 \mathrm{x} \mathrm{g}$ for $10 \mathrm{~min}$ at room temperature, the supernatant platelet-rich plasma was supplemented with PGE1 $(0.5 \mu \mathrm{M})$ and heparin $(6.4 \mathrm{IU} / \mathrm{ml})$, then incubated for $10 \mathrm{~min}$ at $37^{\circ} \mathrm{C}$ and centrifuged at $500 \mathrm{x}$ g for $10 \mathrm{~min}$ at the same temperature.
Freshly isolated platelets were suspended in $5 \mathrm{ml}$ Tyrode's solution, (pH 7.3; containing $\mathrm{NaCl} 137 \mathrm{mM}, \mathrm{KCl} 2.7 \mathrm{mM}$, $\mathrm{MgCl}_{2} 2.1 \mathrm{mM}, \mathrm{NaH}_{2} \mathrm{PO}_{4} 0.4 \mathrm{mM}, \mathrm{NaHCO}_{3} 11.9 \mathrm{mM}$ and glucose $11.1 \mathrm{nM})$. Then apyrase $(1.0 \mathrm{U} / \mathrm{ml})$, PGE1 $(0.5 \mu \mathrm{M})$ and heparin $(6.4 \mathrm{IU} / \mathrm{ml})$ were added, and the mixture was incubated for $10 \mathrm{~min}$ at $37^{\circ} \mathrm{C}$ and adjusted to $\sim 4.5 \times 10^{8}$ platelets $/ \mathrm{ml}$.

Platelet aggregation. The turbidimetric method was applied to measure platelet aggregation, using a Lumi-Aggregometer (Payton, Ontario, Canada). Platelet suspensions $\left(4.5 \times 10^{8}\right.$ platelets $/ \mathrm{ml}$ ) were preincubated at $37^{\circ} \mathrm{C}$ with various concentrations of GalN (300-600 $\mu \mathrm{M})$ or an isovolumetric solvent control (PBS) for 3 and 180 min prior to the addition of collagen $(1 \mu \mathrm{g} / \mathrm{ml})$. Additionally, GalN (300-600 $\mu \mathrm{M})$ was also preincubated for $3 \mathrm{~min}$ at $37^{\circ} \mathrm{C}$ prior to the addition of a subthreshold concentration of collagen $(0.5 \mu \mathrm{g} / \mathrm{ml})$. The reaction was allowed to proceed for $6 \mathrm{~min}$ and the extent of aggregation was expressed in light-transmission units.

Isolation of primary mouse hepatocytes. Ten male C57/BL6 mice (6-8 weeks and 25 $\pm 5 \mathrm{~g}$ ) were purchased from BioLASCO (Taipei, Taiwan). All animal experiments and care procedures were approved by the Institutional Animal Care and Use Committee of Taipei Medical University. The mice were housed in sterilized cages in a 12 -h dark/light cycle at $20 \pm 1^{\circ} \mathrm{C}$ and $60 \pm 10 \%$ humidity with food and water ad libitum. Before undergoing the experimental procedures, all animals were clinically normal and free from apparent infection, inflammation, or neurologic deficits.

Mouse hepatocyte isolation was performed with collagenase perfusion as described by Sun et al (17). Specifically, the portal vein was cannulated using a 22-gauge intravenous catheter and the liver was perfused with calcium-free Krebs bicarbonate buffer followed by collagenase [30 mg 494 IU/mg collagenase IV (Sigma-Aldrich; Merck KGaA; C-5138)] in $280 \mathrm{ml}$ Krebs bicarbonate containing $1.2 \mathrm{mM} / 1 \mathrm{CaCl}_{2}$ and $1.8 \% \mathrm{BSA}$ (Sigma-Aldrich; Merck KGaA; A-4503). All solutions were maintained at $37^{\circ} \mathrm{C}$ and aerated using $95 \% \mathrm{O}_{2}$ and $5 \% \mathrm{CO}_{2}$. The partially digested liver was excised, passed over 60- $\mu$ m nylon mesh and resuspended in Wilson medium (Sigma-Aldrich; Merck KGaA; W-4125) with insulin (Sigma-Aldrich; Merck $\mathrm{KGaA}$; I-0516; $1 \mathrm{U} / \mathrm{dl}$ ) and certified $10 \%$ fetal bovine serum (Gibco; Thermo Fisher Scientific, Inc., Waltham, MA, USA; BRL 16000-044). Hepatocytes were purified by centrifugation with the Wilson medium at $50 \mathrm{x}$ g for $5 \mathrm{~min}$ at room temperature and then resuspended in Wilson medium following a second centrifugation at $80 \mathrm{x}$ for $5 \mathrm{~min}$ at room temperature in a gradient of $50 \%$ Percoll-Wilson medium.

The viability of the hepatocytes, which were maintained $>85 \%$ confluency during the experiment, was determined using trypan blue $(0.008 \%)$ staining for $5 \mathrm{~min}$ at room temperature. The cell concentration was adjusted to $3 \times 10^{5}$ cells $/ \mathrm{ml}$ with the isolated hepatocytes, then placed in a microtiter plate in an incubator maintained at $5 \% \mathrm{CO}_{2}$ at $37^{\circ} \mathrm{C}(18)$ and visualized using a light microscope (Olympus Optical, CHT, Japan).

Measurement of free radicals in platelet suspensions and primary mouse hepatocytes by ESR spectrometry. The ESR spectrometry method was applied using a Bruker EMX ESR spectrometer as described previously (19), with some 
minor modifications. The culture medium was replaced with PBS solution prior to each experiment. Each $150 \mu$ l platelet suspension $\left(4.5 \times 10^{8}\right.$ platelets $\left./ \mathrm{ml}\right)$ and mouse hepatocytes ( $3 \times 10^{5}$ cells $/ \mathrm{ml}$ ) were pre-warmed to $37^{\circ} \mathrm{C}$ for $2 \mathrm{~min}$, and then the enzyme inhibitors or other reagents $[10 \mu \mathrm{M}$ indomethacin (COX inhibitor), AA861 (LOX inhibitor) and $30 \mu \mathrm{M} \mathrm{ABT}$ (a non-isoform specific cytochrome P450 inhibitor)] were added 3 min prior to the addition of GalN $(600 \mu \mathrm{M})$ and AA $(100 \mu \mathrm{M})$. ESR spectra were recorded at room temperature using a quartz flat cell designed for aqueous solutions. The dead time of sample preparation and ESR analysis was exactly $30 \mathrm{sec}$ following the last addition. The conditions of ESR spectrometry were as follows: $20 \mathrm{~mW}$ power at $9.78 \mathrm{GHz}$, with a scan range of $100 \mathrm{G}$ and a receiver gain of $5 \times 10^{4}$. The modulation amplitude, sweep time and time constant are given in the legends to the figures. The ESR spectrum analysis was performed by using WIN-EPR, version 921201 supplied by BRUKER-FRANZEN Analytik GmbH (Bremen, Germany).

Measurement of Fenton reaction induced $\mathrm{OH}^{\bullet}$ formation by ESR. The ESR method was used as described previously (20). A Fenton reaction solution $\left(50 \mu \mathrm{M} \mathrm{FeSO}_{4}+2 \mathrm{mM} \mathrm{H}_{2} \mathrm{O}_{2}\right)$ was pretreated with a solvent control (PBS) for $1 \mathrm{~min}$ with or without GalN and thioacetamide (300-600 $\mu \mathrm{M})$. The ESR spectrum analysis was performed by using WIN-EPR, version 921201 supplied by BRUKER-FRANZEN Analytik GmbH.

Statistical analysis. Experimental results are expressed as the mean \pm standard error of the mean and are accompanied by the number (n) of observations. Data were assessed using an analysis of variance followed by the Newman-Keuls post hoc test for multiple comparisons. All statistical tests were carried out using SigmaPlot version 10 software (Systat Software Inc., San Jose, USA). $\mathrm{P}<0.05$ was considered to indicate a statistically significant difference.

\section{Results}

GalN stimulated hydroxyl radical production in human platelet suspension. The ESR spin-trapping technique was employed to detect free radical production during the reaction between the platelet suspension and GalN. In the absence of GalN-induced stimulation, only weak spin trapping of the hydroxyl radical $\left(\mathrm{OH}^{\circ}\right)$ was detected with DMPO (Fig. 1A). By contrast, a typical concentration dependent 4-line $\mathrm{OH}^{*}$ signal $\left(\mathrm{a}^{\mathrm{N}}=\mathrm{a}^{\mathrm{H}}=14.8 \mathrm{G}\right)$ was detected when GalN $(150-600 \mu \mathrm{M})$ was reacted with the human platelet suspension in the presence of $100 \mathrm{mM}$ DMPO (Fig. 1Ab-Ad). DMSO, an amphiphilic compound, which acted as a free radical scavenger (Fig. 1Ae), effectively scavenged these radicals. In addition, similar radical signals were observed in thioacetamide treated platelet suspension to that detected in PBS treated platelets (Fig. 1Af), which indicated that $\mathrm{OH}^{*}$ signals produced in the platelet suspension are dependent upon the type of inducer used in the spin trapping reaction. Fig. 1B illustrates the statistical analysis of results presented in $1 \mathrm{~A}$, in which GalN significantly induced a 4-line $\mathrm{OH}^{*}$ signal in a dose-dependent manner $(150-600 \mu \mathrm{M})$. Moreover, GalN at a concentration of $600 \mu \mathrm{M}$, induced the highest significant $\mathrm{OH}^{*}$ signal compared to PBS $(\mathrm{P}<0.001)$, but this signal was significantly reversed by DMSO $(\mathrm{P}<0.001)$.
A

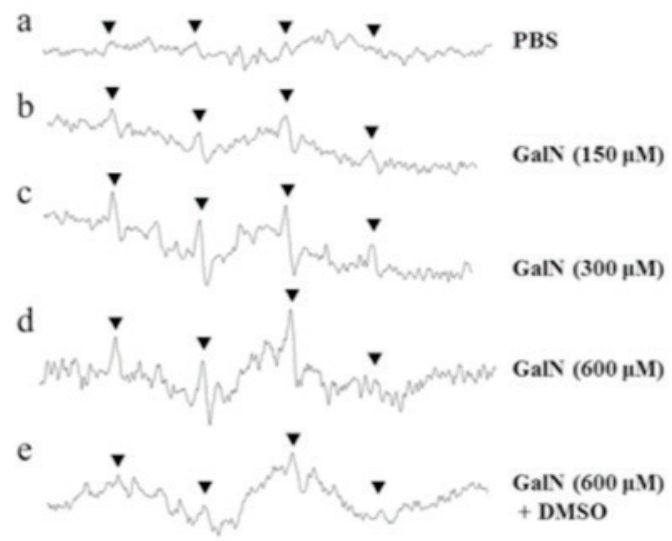

f

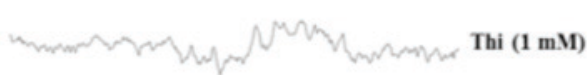

B

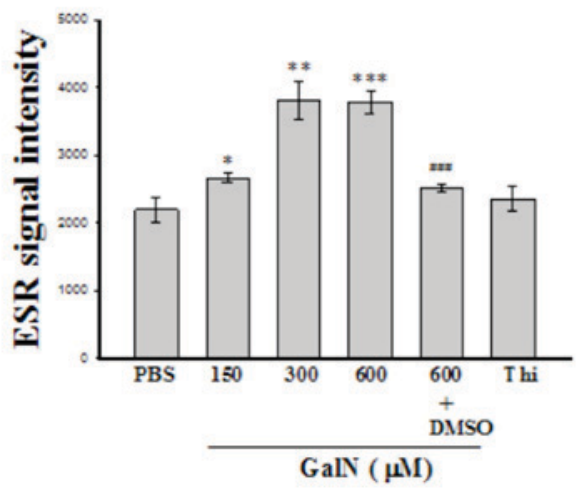

Figure 1. Analysis of ESR spectra. (A) ESR spectra detected from the reaction of human platelet suspensions with GalN in the presence of DMPO. (a) Human platelets $\left(4.5 \times 10^{8}\right.$ platelets $\left./ \mathrm{ml}, 150 \mu \mathrm{l}\right)$ were preincubated with DMPO $(100 \mathrm{mM})$ followed by the addition of GalN at (b) 150 , (c) 300 and (d) $600 \mu \mathrm{M}$. (e) $600 \mu \mathrm{M}$ GalN plus $1 \%$ DMSO. (f) Human platelets $\left(4.5 \times 10^{8}\right.$ platelets $\left./ \mathrm{ml}, 150 \mu \mathrm{l}\right)$ preincubated with DMPO and then $1 \mathrm{mM}$ thio was added. Instrument parameters were as follows: Modulation amplitude, 1 G; time constant, $164 \mathrm{msec}$; scanning for $42 \mathrm{sec}$ with 10 scans accumulated. The ESR spectra are labeled to show their components: DMPO-hydroxyl radical adducts $(\boldsymbol{\nabla})$. (B) Statistical data are presented as the mean \pm standard error of the mean $(n=4) .{ }^{*} \mathrm{P}<0.05 ;{ }^{* * *} \mathrm{P}<0.01$ and ${ }^{* * *} \mathrm{P}<0.001$, vs. the reaction of PBS treated platelets; ${ }^{\# \# \#} \mathrm{P}<0.001$, vs. the reaction of GalN $(600 \mu \mathrm{M})$ incubated platelets. GalN, D-galactosamine; ESR, electron spin resonance; DMPO, 5,5-dimethyl-1-pyrroline $N$-oxide; Thi, thioacetamide.

Role of $\mathrm{COX} / \mathrm{LOX}$ in GalN-induced $\mathrm{OH}^{*}$ in human platelets. Since COX and LOX products derived from AA, such as prostaglandins and leukotrienes, are associated with pathogenic mediators in endotoxemia, the inhibitors of these enzymes were employed in order to determine whether they serve a role in GalN-induced $\mathrm{OH}^{*}$ production in human platelets. Platelets were incubated with $10 \mu \mathrm{M}$ indomethacin (COX inhibitor), AA861 (LOX inhibitor) and $30 \mu \mathrm{M}$ ABT (a non-isoform specific cytochrome $\mathrm{P} 450$ inhibitor) 3 min prior to the addition of GalN. The results demonstrated that in the presence of indomethacin, GalN generated a condensed $(84.3 \pm 1.7 \%)$ ESR signal intensity, however, AA861 and ABT demonstrated no significant effect (8.7 \pm 9.3 and $24.8 \pm 14.8 \%$, respectively) in this reaction system (Fig. 2A). These observations suggested a role for COX enzyme in the generation of GalN-induced $\mathrm{OH}^{*}$ in human platelets. 
A
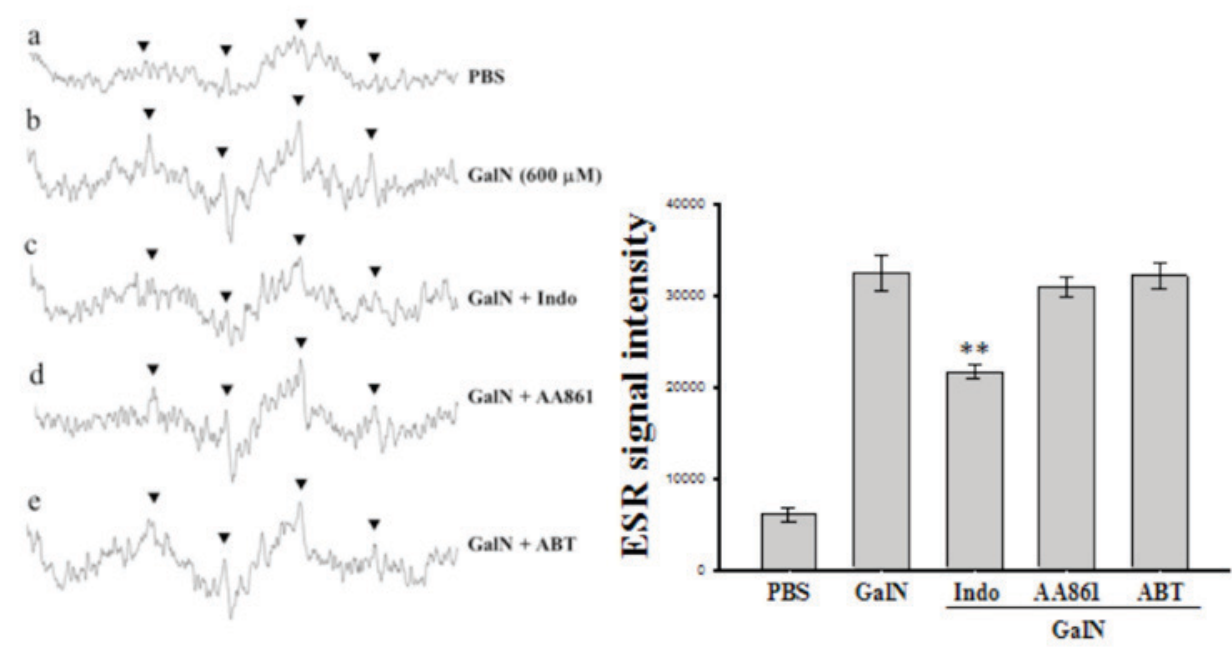

B
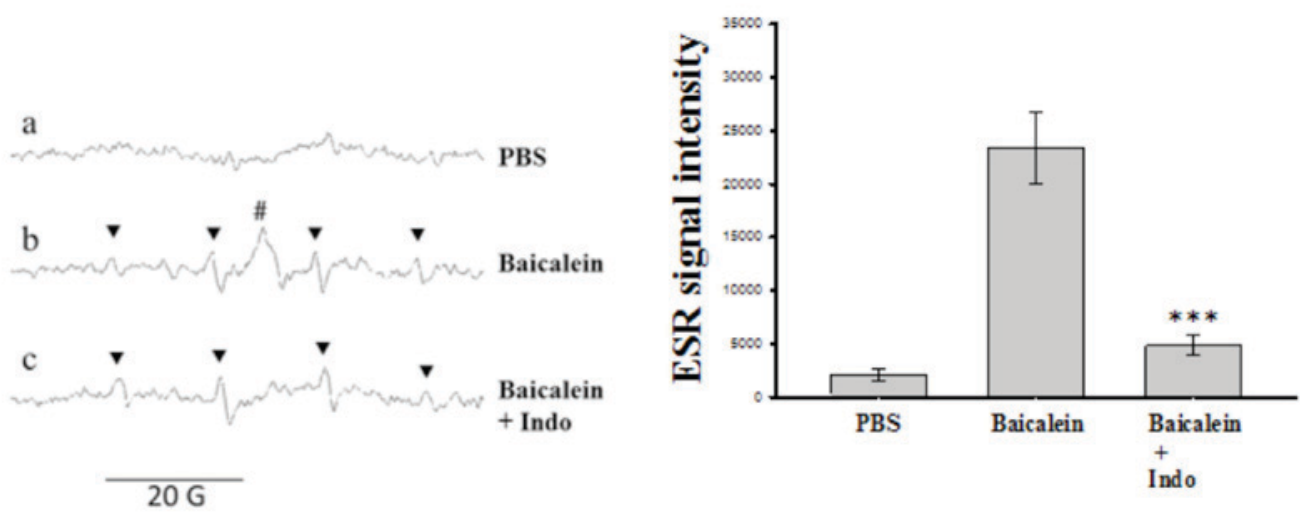

Figure 2. Effects of various inhibitors on GalN-induced hydroxyl radical formation in washed human platelets. (A) The reaction mixture contained human platelet suspensions $\left(4.5 \times 10^{8}\right.$ platelets $\left./ \mathrm{ml} ; 150 \mu \mathrm{l}\right)$ with (a) DMPO $(100 \mathrm{mM})$ and (b) GalN (600 $\left.\mu \mathrm{M}\right)$. The inhibitors of (c) indo (10 $\left.\mu \mathrm{M}\right)$, (d) AA861 (10 $\left.\mu \mathrm{M}\right)$ and (e) ABT $(30 \mu \mathrm{M})$ were added to the GalN $(600 \mu \mathrm{M})$ contained platelet suspensions. The instrument parameters were the same as those in Fig. 1. ${ }^{* *} \mathrm{P}<0.01$, vs. the reaction of GalN incubated platelets. (B) Effects of indo on baicalein induced semiquinone and hydroxyl radical formation in washed human platelets. (a) Human platelets $\left(4.5 \times 10^{8}\right.$ platelets $\left./ \mathrm{ml}, 150 \mu \mathrm{l}\right)$ were preincubated with DMPO $(100 \mathrm{mM})$ followed by the addition of baicalein at (b) $300 \mu \mathrm{M}$, and (c) baicalein $300 \mu \mathrm{M}+$ indomethacin $(10 \mu \mathrm{M})$. The ESR spectra are labeled to demonstrate their components: DMPO-hydroxyl radical adducts ( $\mathbf{\nabla}$, Panel A); DMPO-semiquinone radical adduct (\#, Panel B). Data are presented as the mean \pm standard error of the mean $(\mathrm{n}=4)$. ${ }^{* * *} \mathrm{P}<0.001$, vs. the reaction of baicalein treated platelets. ${ }^{* *} \mathrm{P}<0.01$, vs. the reaction of GaIN treated platelets. DMPO, 5,5-dimethyl-1-pyrroline $N$-oxide; GalN, D-galactosamine; ABT, 1-aminobenzotriazole; Indo, indomethacin; ESR, electron spin resonance.

Spin trapping of the baicalein-induced semiquinone radicals in human platelets. The result suggesting that the COX enzyme mediated GalN-induced $\mathrm{OH}^{*}$ in human platelets was further investigated using the COX inhibitor indomethacin on baicalein-induced semiquinone radicals in a platelet suspension. Fig. 2A demonstrates that indomethacin significantly $(\mathrm{P}<0.01)$ inhibited GalN induced $\mathrm{OH}^{*}$ formation. Application of baicalein significantly induced semiquinone radicals as well as $\mathrm{OH}^{\circ}$; however, the $\mathrm{COX}$ inhibitor indomethacin suppressed baicalein-induced semiquinone radicals (Fig. 2B) without affecting the induced $\mathrm{OH}^{*}$ formation. Therefore, it was confirmed that COX serves a role in the formation of GalN-induced $\mathrm{OH}^{*}$ in platelets and LOX may involve baicalein induced $\mathrm{OH}^{*}$ in this reaction system.

GalN potentiates AA-induced carbon-centered free radicals in mouse primary hepatocytes. A previous study demonstrated that carbon-centered lipid-derived radicals are an intermediate of enhanced oxidative stress product of lipid peroxidation in the liver (21). In the present study, it was demonstrated that a six-line ESR signal $\left(\mathrm{a}^{\mathrm{N}}=15.9 \mathrm{G}, \mathrm{a}^{\mathrm{H}}=22.8 \mathrm{G}\right)$ was produced when the DMPO/hepatocyte-derived adduct was subjected to AA (Fig. 3A). In the control reactions, without AA, GalN produced no ESR signal (Fig. 3Aa). This six-line signal of carbon-centered radicals stimulated by AA was concentration dependently potentiated by GalN (Fig. 3Ab-e). The identity of the radical species was presumed to be a carbon-centered radical adduct that could be proved based on the close resemblance of the hyperfine coupling constants of the observed signal (22).

Role of cytochrome P450 on AA-induced carbon-centered radicals in hepatocytes. GalN induced cytochrome $\mathrm{P} 450$ generate ROS that are known to have greater chemical toxicity (23). A significant increase in hepatic cytochrome P450 mRNA and protein expression was previously established in the GalN-intoxicated rats (23). Supplementation with carvacrol, 

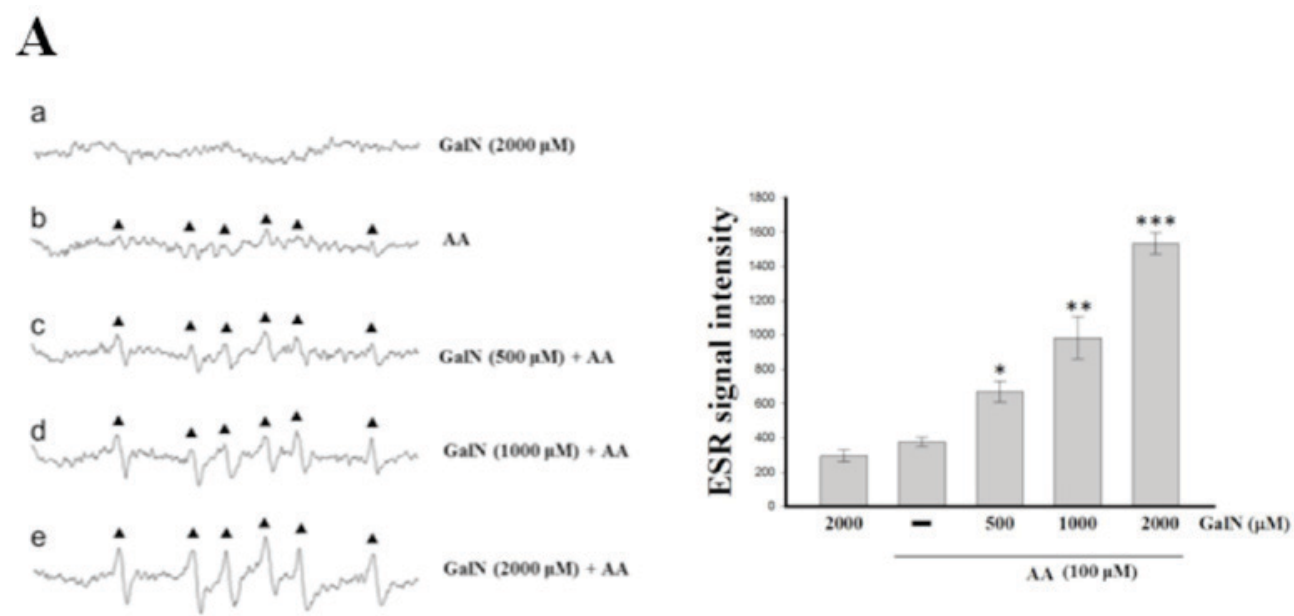

B
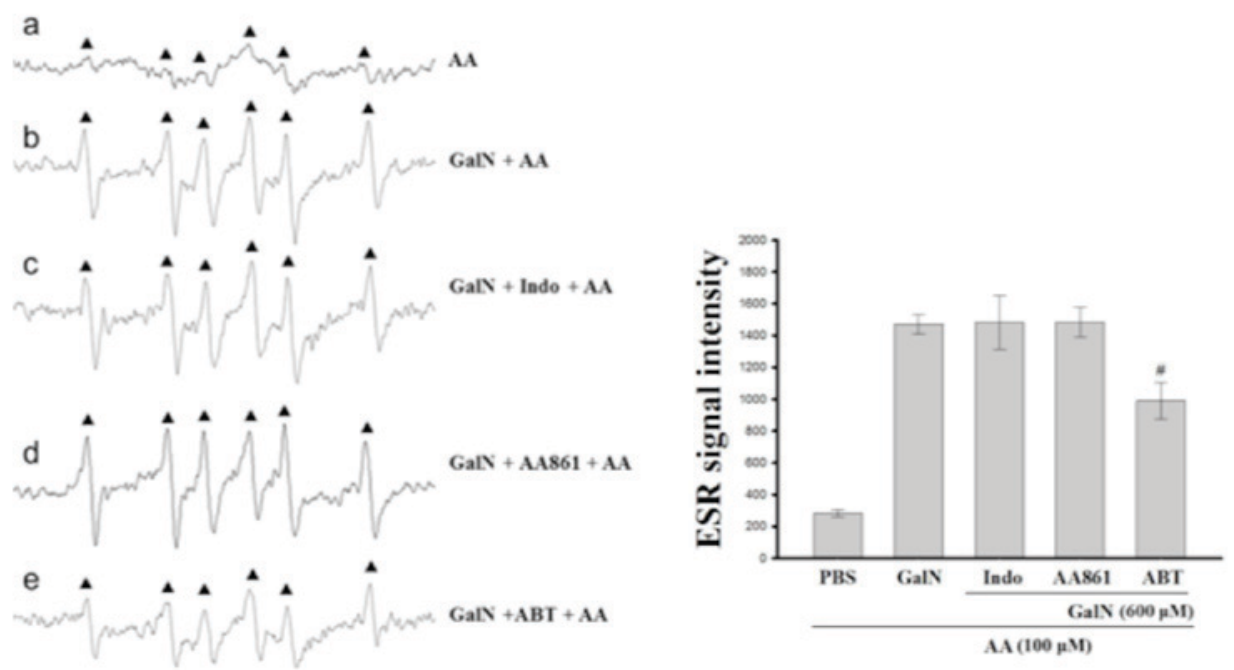

Figure 3. ESR spectra analysis for GalN and different inhibitor treated hepatocytes. (A) GalN potentiated the AA induced carbon-centered radical formation in primary mouse hepatocytes. Mouse hepatocytes $\left(3 \times 10^{5}\right.$ cells $\left./ \mathrm{ml}, 150 \mu \mathrm{l}\right)$ were incubated with DMPO $(100 \mathrm{mM})$ followed by the addition of GalN at (a) $2,000 \mu \mathrm{M}$ and (b) AA $100 \mu \mathrm{M}$. GalN (c) 500, (d) 1,000 and (e) 2,000 $\mu \mathrm{M}$ was added to the AA pretreated hepatocytes. (B) Effects of (a) AA induced carbon-centered radical formation (b) with GalN potentiation and (c) indo, (d) AA861 and (e) ABT. Instrument parameters were as follows: Modulation amplitude, 1 G; time constant, $164 \mathrm{msec}$; scanning for $42 \mathrm{sec}$ with six scans accumulated. The ESR spectra are labeled to show their components: DMPO-carbon-centered radical adduct $(\mathbf{\Lambda})$. Data are presented as the mean \pm standard error of the mean $(\mathrm{n}=4) .{ }^{*} \mathrm{P}<0.05 ;{ }^{* * *} \mathrm{P}<0.01$ and ${ }^{* * *} \mathrm{P}<0.001$, vs. the reaction of AA treated hepatocytes; ${ }^{\text {"}} \mathrm{P}<0.05$, vs. the reaction of AA pretreated GalN + inhibitor treated platelets. ESR, electron spin resonance; GalN, D-galactosamine; AA, arachiodonic acid; DMPO, 5,5-dimethyl-1-pyrroline $N$-oxide; indo, indomethacin; ABT, 1-aminobenzotriazole.

a predominant monoterpenic phenol, suppressed cytochrome P450 mRNA and protein expression in GalN induced rats (23). Therefore, evaluation of whether cytochrome P450 serves role in AA-induced carbon-centered radicals in hepatocytes was performed. As expected, the results demonstrated that GalN potentiated the AA-induced six-line signals of carbon-centered radical, which was inhibited by a non-isoform specific cytochrome $\mathrm{P} 450$ inhibitor, though not by COX or LOX inhibitors (Fig. 3Ba-e), indicating that cytochrome P450 may serve a role in GalN potentiation of AA-induced carbon-centered radicals in hepatocytes.

Involvement of COX and cytochrome P450 in GalN-stimulated radicals was confirmed using a cell free Fenton reaction system. A cell free Fenton reaction containing iron and $\mathrm{H}_{2} \mathrm{O}_{2}$ was studied in the absence or presence of GalN and thioacetamide to elucidate the role of endogenous enzymes COX and cytochrome P450 in GalN-induced free radicals in cell systems (platelets and hepatocytes). As presented in Fig. 4, GalN and thioacetamide did not produce $\mathrm{OH}^{*}$ in the cell free Fenton reaction system, as they demonstrated very similar signal spectra to that of the PBS only treated reaction. These results suggested that the endogenous enzymes of COX, LOX and cytochrome p450 may require GalN inducing free radicals in the cell systems.

GalN on platelet aggregation. Khandoga et al (24) hypothesized that activated platelets may be able to generate ROS and possess the potential to induce liver injury. Despite the apparent involvement of platelets in liver injury, Woolbright and Jaeschke (25) questioned whether the available reports clearly corroborate a mediatory role of platelets in post-ischemic liver injury or platelet activation. Therefore, the present study 


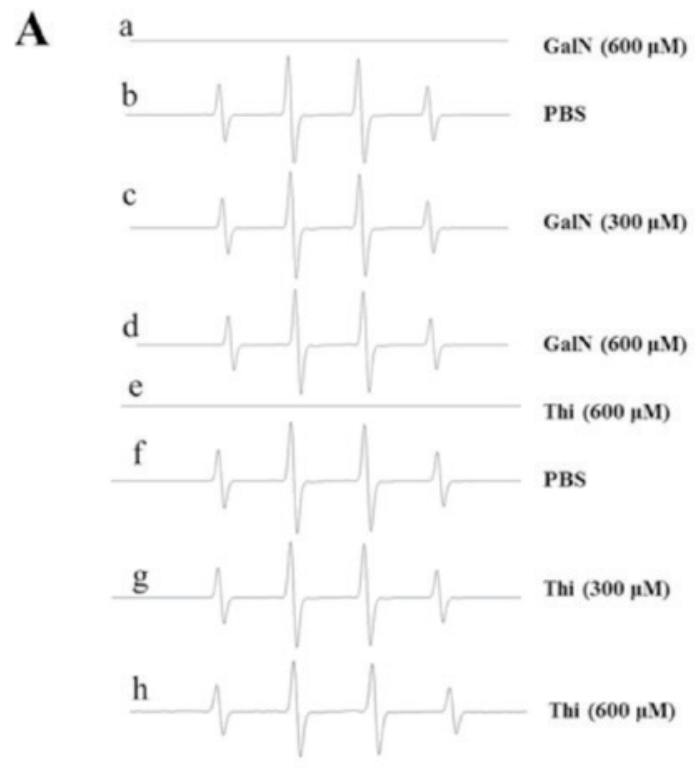

B

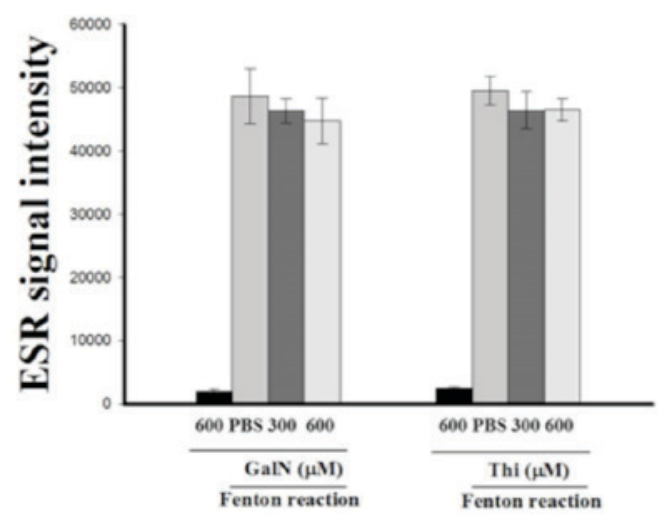

Figure 4. Fenton reaction analysis. Effects of GalN and Thi on the cell free Fenton reaction system. (A) GalN $(600 \mu \mathrm{M})$ dissolved in PBS without Fenton reaction (a), Fenton reaction in solvent control (PBS) (b), and GalN (300 and $600 \mu \mathrm{M}$ ) (c and d). Similarly, thioacetamide (Thi) was analyzed in cell free Fenton reaction system (e-h). Instrument parameters were as follows: Modulation amplitude, $1 \mathrm{G}$; time constant, 164 msec; scanning for $42 \mathrm{sec}$. (B) Quantitative analysis of the ESR signal intensity. Statistical data are presented as the mean \pm standard error of the mean $(n=4)$. ESR, electron spin resonance.

evaluated whether GalN induces platelet aggregation and whether GalN induced $\mathrm{OH}^{*}$ production is dependent on its agrregatory effects. GalN (300 and $600 \mu \mathrm{M})$ did not induce platelet aggregation when stimulated with short (3 min) or long (180 min) periods of incubation (Fig. 5A and B) in the human platelet suspensions. In addition, GalN for $120 \mathrm{~min}$ incubation with the same concentrations (300 and $600 \mu \mathrm{M})$ did not affect collagen-induced aggregation (Fig. 5C). This result indicated that GalN induced free radical formation in platelets is not a result of the induction of platelet aggregation.

\section{Discussion}

The present study utilized ESR spin trapping techniques to detect the free radical formation stimulated induced by GalN in platelets and primary mouse hepatocytes, and also established the potential role of endogenous enzymes in this phenomenon. The results demonstrated that GalN stimulates $\mathrm{OH}^{\circ}$ and baicalein induces semiquinone radicals in platelets, these radicals were suppressed by a COX inhibitor. GalN also potentiated AA-induced carbon-centered radicals in mouse hepatocytes and was inhibited by cytochrome P450 inhibitor. However, a cell free Fenton reaction system demonstrated that GalN did not induce radical formation and also did not respond to platelet aggregation when it was incubated alone or in collagen pretreated platelets.

Cardiac cirrhosis or congestive hepatopathy includes a spectrum of hepatic imbalances arising from right-sided heart failure (26). GalN is a hepatotoxic agent metabolized exclusively in hepatocytes. The administration of GalN causes the development of lethal liver injury, which resembles the biochemical and metabolic alterations observed in severe hepatic failure (27). Oxygen free radicals have been implicated in the pathogenesis of toxic liver injury (28), and oxidative stress during liver cirrhosis is responsible for cardiac dysfunction (29). As free radicals in biological systems are characterized by their high reactivity, short lifetimes and low concentrations, the type of spin trap used is a key factor in determining how informative and sensitive the spin trapping technique may be for a given radical species. In the present study, the frequently used spin trap DMPO was used. DMPO possesses significant advantages over other nitrone spin traps, as it is the most redox inactive and has a comparatively higher dependence on the structure of the trapped radical in ESR spectra than the common nitrone spin traps, including $\alpha$-phenyl- $N$-tert-butylnitrone and $\alpha$-(4-pyridyl-1-oxide)$N$-tert-butylnitrone.

Platelets are highly active, anucleate cells, that are rich in two representative peroxidase systems, prostaglandin $\mathrm{H}$ synthase (PHS) and 12-LOX, a subtype of LOX (30). These enzymes serve an active role in platelet function through the production of bioactive mediators from AA including thromboxane A2, 12-hydroxyperoxyeicosatetraenoic acid and 12-hydroxyeicosatetraenoic acid (31). Furthermore, platelets have been frequently reported as a vulnerable target of xenobiotic-induced cytotoxicity and peroxidase action on xenobiotic compounds may contribute to platelet cytotoxicity. The authors' previous study (32) demonstrated that 12-LOX and PHS were involved in $\mathrm{OH}^{*}$ formation induced by natural flavonoids in platelets and suggested a role for these peroxidase systems in the xenobiotic-compound activation. COX-2 has been recognized as a potent pro-inflammatory cytokine and has been implicated in platelet aggregation (33). COX-2 inhibitory activity has previously been reported to be associated with 1,1-diphenyl-2-picrylhydrazyl radical scavenging activity (34). In the present study, $\mathrm{OH}^{\bullet}$ production by GalN in platelets was significantly suppressed by the COX inhibitor, however, not by the LOX or cytochrome $\mathrm{P} 450$ inhibitor, suggesting that COX may serve a vital role in GalN stimulated $\mathrm{OH}^{*}$ formation in platelets.

It has been suggested that the autoxidation of flavonoids generates semiquinone radicals and superoxide radicals (35). Semiquinone free radicals were also generated when polyphenols were incubated with $\mathrm{H}_{2} \mathrm{O}_{2}$ (36). The authors' earlier study demonstrated that semiquinone free radicals were generated when baicalein was incubated with $\mathrm{H}_{2} \mathrm{O}_{2}$ or platelets/AA, and also demonstrated that baicalein-induced $\mathrm{OH}^{*}$ formation in 
A
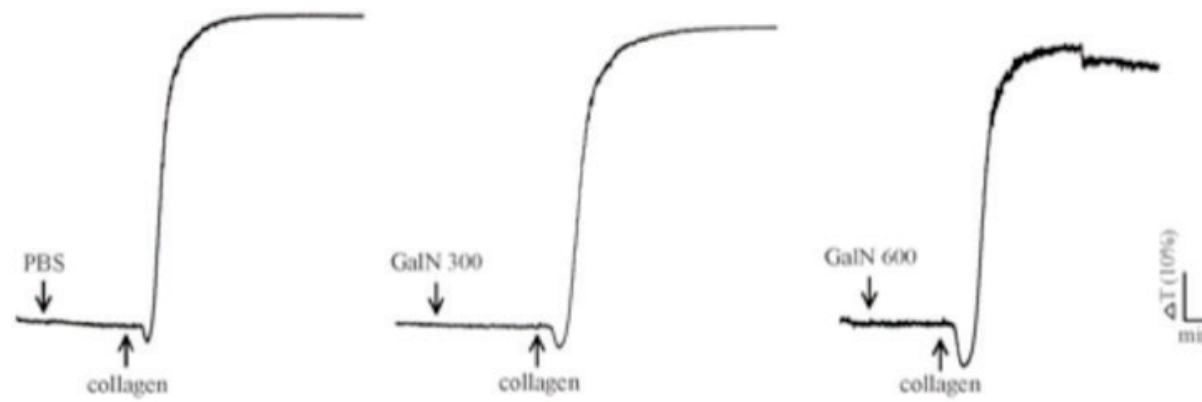

B
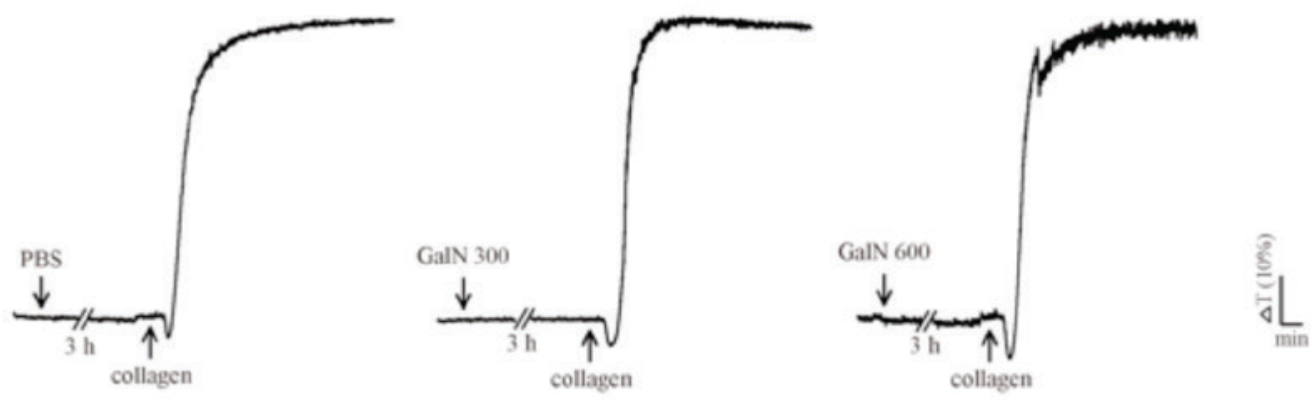

C

a

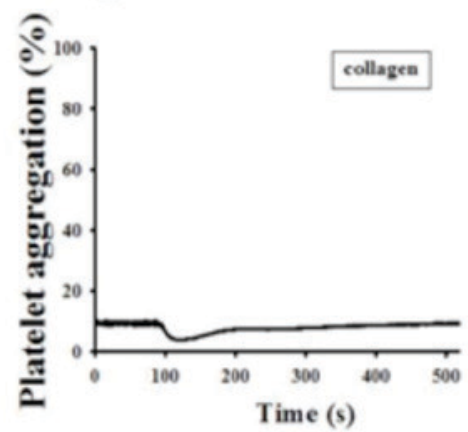

b

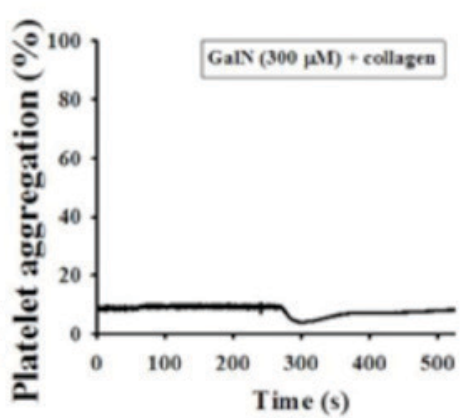

c

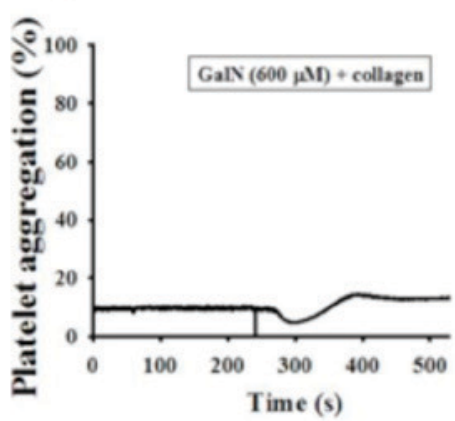

Figure 5. Effects of GalN on platelet aggregation in washed human platelets. (A) Washed platelets (3.6x10 8 cells $/ \mathrm{ml} ; 500 \mu \mathrm{l})$ were preincubated with GalN (300 and $600 \mu \mathrm{M}$ ) for $3 \mathrm{~min}$ or (B) $3 \mathrm{~h}$ followed by the addition of collagen ( $1 \mu \mathrm{g} / \mathrm{ml}$ ) for 6 min to trigger platelet aggregation. (C) Effects of (a) collagen, (b) GalN $(300 \mu \mathrm{M})$ and collagen and (c) GalN $(600 \mu \mathrm{M})$ and collagen on platelet aggregation. A nonaggregating subthreshold concentration of collagen $(0.5 \mu \mathrm{g} / \mathrm{ml})$ was used. The profiles are representative examples of four repeated experiments $(\mathrm{n}=4)$. GalN, D-galactosamine; min, min; $\mathrm{T}$, transmission.

human platelets is independent of autoxidation reactions (32). A previous study has also demonstrated that baicalein inhibited 12-LOX activity without affecting COX in human platelets (37). In the present study, in platelets the baicalein-stimulated semiquinone free radicals were inhibited by the COX inhibitor without affecting the formation of $\mathrm{OH}^{\circ}$. Therefore, it was hypothesized that baicalein may produce $\mathrm{OH}^{\bullet}$ via LOX in human platelets.

Greenley and Davies (38) used ESR spin trapping to demonstrate the production of free radicals in rat liver microsomal preparations. In the present study, the free radicals reacted with a nitrone or nitroso compound to form a relatively stable ESR detectable radical adduct. In addition, the peroxyl and carbon-centered radical adducts were detected in rat liver microsomes (38). Cytochrome $\mathrm{P} 450$ belongs to a superfamily of haem proteins responsible for the metabolic activation or inactivation of the majority of clinically used drugs and a number of toxins. A previous study has demonstrated that cytochrome $\mathrm{P} 450$ isoforms and their activities are suppressed in animal models of endotoxemia as well as in cultured hepatocytes stimulated by endotoxin (39). The inactivation of the P450 enzyme can be attributed to the formation of a carbon-centered free radical intermediate, which may attack the haem prosthetic group of the enzyme (40). To the best of 
our knowledge, the present study demonstrated, for the first time, in vitro generation of carbon-centered free radicals in mouse primary hepatocytes following exposure to AA, and revealed that this production was further potentiated by GalN. The result demonstrating that GalN-potentiated AA-induced carbon-centered radicals were conceivably recovered by the cytochrome P450 inhibitor ABT, indicated that cytochrome P450 may act as an intermediate of GalN enhanced carbon-centered radicals in hepatocytes.

A previous study presented the role of platelets in oxidative stress in the context of hepatic injury (41). In addition, it has also been postulated that platelets are essential for the liver to regenerate properly following a partial liver resection (42). Platelet aggregation has been associated with microvascular perfusion defects, apoptotic cell death, vascular oxidative stress and an inflamed endothelium (43), all suggesting a pathophysiological connection between platelets and hepatocytes. In the present study, $\mathrm{GalN}$ induced $\mathrm{OH}^{*}$ radicals in platelets; however, it did not cause platelet aggregation when analyzed alone or in collagen pretreated conditions. This result demonstrated that platelet activation does not involve the GalN induced production of $\mathrm{OH}^{*}$ radicals.

In conclusion, the present study demonstrated that GalN induces hydroxyl radical formation in platelets without GalN activation or aggregation and potentiated AA-induced carbon-centered free radical in the primary mouse hepatocytes. COX and cytochrome P450 may serve a role in GalN induced free radical production in platelets and hepatocytes, respectively. Thus, the present study provides evidence for the pathophysiological association between platelets and hepatocytes in which free radicals are believed to be involved. This way, GalN holds an important role in inducing free radicals in cardiohepatic diseases, however, a further study is required to confirm this hypothesis.

\section{Acknowledgements}

The present study was supported by grants from the Ministry of Science and Technology of Taiwan (grant nos. MOST103-2320-B-038-017, MOST104-2622-B-038-003 and MOST104-2320-B-038-045-MY2), Cathay General Hospital-Taipei Medical University (grant no. 104CGH-TMU-01-3) and Taipei Medical University-National Taiwan University of Science and Technology (grant no. TMU-NTUST-103-02).

\section{References}

1. Boelsterli UA and Lim PL: Mitochondrial abnormalities-a link to idiosyncratic drug hepatotoxicity? Toxicol Appl Pharmacol 220: 92-107, 2007

2. Gómez-Lechón MJ, Tolosa L, Castell JV and Donato MT: Mechanism-based selection of compounds for the development of innovative in vitro approaches tohepatotoxicity studies in the LIINTOP project. Toxicol In Vitro 24: 1879-1889, 2010.

3. Keppler D, Lesch R, Reutter W and Decker K: Experimental hepatitis induced by D-galactosamine. Exp Mol Pathol 9: 279-290, 1968

4. Quintero A, Pedraza CA, Siendones E, Kamal ElSaid AM, Colell A, García-Ruiz C, Montero JL, De la Mata M, Fernández-Checa JC, Miño G and Muntané J: PGE1 protection against apoptosis induced by D-galactosamine is not related to the modulation of intracellular free radical production in primary culture of rat hepatocytes. Free Radic Res 36: 345-355, 2002.
5. Lekić N, Cerný D, Hořínek A, Provazník Z, Martínek J and Farghali H: Differential oxidative stress responses to D-galactosamine-lipopolysaccharide hepatotoxicity based on real time PCR analysis of selected oxidant/antioxidant andapoptotic gene expressions in rat. Physiol Res 60: 549-558, 2011.

6. Choi JH, Kang JW, Kim DW, Sung YK and Lee SM: Protective effects of Mg-CUD against D-galactosamine-induced hepatotoxicity in rats. Eur J Pharmacol 657: 138-143, 2011.

7. Bruck R, Aeed H, Avni Y, Shirin H, Matas Z, Shahmurov M, Avinoach I, Zozulya G, Weizman N and Hochman A: Melatonin inhibits nuclear factor kappa B activation and oxidative stress and protects against thioacetamide induced liver damage in rats. J Hepatol 40: 86-93, 2004.

8. von Sonntag C: Free-radical-induced DNA damage and its repair. Springer-Verlag, Berlin, 2006.

9. Black M: Acetaminophen hepatotoxicity. Annu Rev Med 35: 577-593, 1984.

10. Lam FW, Vijayan KV and Rumbaut RE: Platelets and their interactions with other immune cells. Compr Physiol 5: 1265-1280, 2015.

11. van Golen RF, van Gulik TM and Heger M: Mechanistic overview of reactive species-induced degradation of the endothelial glycocalyx during hepatic ischemia/reperfusion injury. Free Radic Biol Med 52: 1382-1402, 2012.

12. Khandoga A, Biberthaler P, Enders G, Axmann S, Hutter J, Messmer K and Krombach F: Platelet adhesion mediated by fibrinogen-intercelllular adhesion molecule-1 binding induces tissue injury in the postischemic liver in vivo. Transplantation 74: 681-688, 2002

13. Cook JA: Eicosanoids. Crit Care Med 33 (12 Suppl): S488-S491, 2005.

14. Ito S, Ito Y, Katagiri H, Suzuki T, Hoka S, Yokomizo T, Shimizu T and Majima M: Leukotriene B4/leukotriene B4 receptor pathway is involved in hepatic microcirculatory dysfunction elicited by endotoxin. Shock 30: 87-91, 2008.

15. Reddy RC, Chen GH, Tateda K, Tsai WC, Phare SM, Mancuso P, Peters-Golden $\mathrm{M}$ and Standiford TJ: Selective inhibition of COX-2 improves early survival in murine endotoxemia but not in bacterial peritonitis. Am J Physiol Lung Cell Mol Physiol 281: L537-L543, 2001.

16. Hsiao G, Lin KH, Chang Y, Chen TL, Tzu NH, Chou DS and Sheu JR: Protective mechanisms of inosine in platelet activation and cerebral ischemic damage. Arterioscler Thromb Vasc Biol 25: 1998-2004, 2005.

17. Sun P, Zhang P, Wang PX, Zhu LH, Du Y, Tian S, Zhu X and Li H: Mindin deficiency protects the liver against ischemia/reperfusion injury. J Hepatol 63: 1198-1211, 2015.

18. Hsu YP, Chen RJ, Fang JF, Lin BC, Huang TL, Cheng ML, Chiu DT and Tsay PK: Increased susceptibility to oxidant injury in hepatocytes from rats with intra-abdominal hypertension. J Trauma 57: 569-575, 2004.

19. Chou DS, Hsiao G, Lai YA, Tsai YJ and Sheu JR: Baicalein induces proliferation inhibition in B16F10 melanoma cells by generating reactive oxygen species via 12-lipoxygenase. Free Radic Biol Med 46: 1197-1203, 2009.

20. Chou DS, Hsiao G, Shen MY, Tsai YJ, Chen TF and Sheu JR: ESR spin trapping of a carbon-centered free radical from agonist-stimulated human platelets. Free Radic Biol Med 39: 237-248, 2005

21. Shvedova AA, Kisin ER, Murray AR, Mouithys-Mickalad A, Stadlerd K, Masond RP and Kadiisk M: ESR evidence for in vivo formation of free radicals in tissue of mice exposed to single-walled carbon nanotubes. Free Radic Biol Med 73: 154-165, 2014.

22. Qian SY, Wang HP, Schafer FQ and Buettner GR: EPR detection of lipid-derived free radicals from PUFA, LDL, and cell oxidations. Free Radic Biol Med 29: 568-579, 2000.

23. Aristatile B, Al-Assaf AH and Pugalendi KV: Carvacrol ameliorates the PPAR-A and cytochrome p450 expression on D-galactosamine induced hepatotoxicity rats. Afr J Tradit Complement Altern Med 11: 118-123, 2014.

24. Khandoga A, Biberthaler P, Messmer K and Krombach F: Platelet-endothelial cell interactions during hepatic ischemia-reperfusion in vivo: A systematic analysis. Microvasc Res 65: 71-77, 2003.

25. Woolbright BL and Jaeschke H: Heme oxygenase-1 and platelets in hepatic ischemia reperfusion injury. J Gastroenterol Hepatol 28: 756-757, 2013.

26. Kubo SH, Walter BA, John DH, Clark M and Cody RJ: Liver function abnormalities in chronic heart failure. Influence of systemic hemodynamics. Arch Intern Med 147: 1227-1230, 1987. 
27. Wu YH, Hu SQ, Liu J, Cao HC, Xu W, Li YJ and Li LJ: Nature and mechanisms of hepatocyte apoptosis induced by D-galactosamine/lipopolysaccharide challenge in mice. Int J Mol Med 33: 1498-1506, 2014.

28. Sumida Y, Niki E, Naito Y and Yoshikawa T: Involvement of free radicals and oxidative stress in NAFLD/NASH. Free Radic Res 47: 869-880, 2013.

29. Yang YY, Liu H, Nam SW, Kunos G and Lee SS: Mechanisms of TNFalpha-induced cardiac dysfunction in cholestatic bile duct-ligated mice: Interaction between TNFalpha and endocannabinoids. J Hepatol 53: 298-306, 2010.

30. Maskrey BH,Bermúdez-Fajardo A,Morgan AH, Stewart-Jones E, Dioszeghy V, Taylor GW, Baker PR, Coles B, Coffey MJ, Kühn H and O'Donnell VB: Activated platelets and monocytes generate four hydroxyphosphatidylethanolamines via lipoxygenase. J Biol Chem 282: 20151-20163, 2007.

31. Johnson EN, Brass LF and Funk CD: Increased platelet sensitivity to ADP in mice lacking platelet-type 12-lipoxygenase. Proc Natl Acad Sci USA 95: 3100-3105, 1998.

32. Chou DS, Lee JJ, Hsiao G, Hsieh CY, Tsai YJ, Chen TF and Sheu JR: Baicalein induction of hydroxyl radical formation via 12-lipoxygenase in human platelets: An ESR study. J Agric Food Chem 55: 649-655, 2007.

33. Morteau O: Prostaglandins and inflammation: The cyclooxygenase controversy. Arch Immunol Ther Exp (Warsz) 48: 473-480, 2000.

34. Ko CH, Shen SC, Lin HY, Hou WC, Lee WR, Yang LL and Chen YC: Flavanones structure-related inhibition on TPA induced tumor promotion through suppression of extracellular signal-regulated protein kinases: Involvement of prostaglandin E2 in anti-promotive process. J Cell Physiol 193: 93-102, 2002.

35. Hodnick WF, Milosavljević EB, Nelson JH and Pardini RS Electrochemistry of flavonoids. Relationships between redox potentials, inhibition of mitochondrial respiration, and production of oxygen radicals by flavonoids. Biochem Pharmacol 37 2607-2611, 1988.
36. Bors W, Michel C and Stettmaier K: Electron paramagnetic resonance studies of radical species of proanthocyanidins and gallate esters. Arch Biochem Biophys 374: 347-355, 2000.

37. You KM, Jong $\mathrm{HG}$ and Kim HP: Inhibition of cyclooxygenase/lipoxygenase from human platelets by polyhydroxylated/methoxylated flavonoids isolated from medicinal plants. Arch Pharm Res 22: 18-24, 1999.

38. Greenley TL and Davies MJ: Radical production from peroxide and peracid tumour promoters: EPR spin trapping studies. Biochim Biophys Acta 1157: 23-31, 1993.

39. Morgan ET: Regulation of cytochrome p450 by inflammatory mediators: Why and how? Drug Metab Dispos 29: 207-212, 2001.

40. Tolando R, Zanovello A, Ferrara R, Iley JN and Manno M: Inactivation of rat liver cytochrome P450 (P450) by N,N-dimethylformamide and N,N-dimethylacetamide. Toxicol Lett 124: 101-111, 2001.

41. van Golen RF, Stevens KM, Colarusso P, Jaeschke H and Heger M: Platelet aggregation but not activation and degranulation during the acute post-ischemic reperfusion phase in livers with no underlying disease. J Clin Transl Res 1: 107-115, 2015.

42. Starlinger $P$, Assinger A, Haegele S, Wanek D, Zikeli S, Schauer D, Birner P, Fleischmann E, Gruenberger B, Brostjan C and Gruenberger T: Evidence for serotonin as a relevant inducer of liver regeneration after liver resection in humans. Hepatology 60 : 257-266, 2014.

43. Mende K, Reifart J, Rosentreter D, Manukyan D, Mayr D, Krombach F, Rentsch M and Khandoga A: Targeting platelet migration in the postischemic liver by blocking proteaseactivated receptor 4. Transplantation 97: 154-160, 2014. 